University of Wollongong

Research Online

Faculty of Engineering and Information

Faculty of Engineering and Information

Sciences - Papers: Part A

Sciences

2007

\title{
Kinetics of transfemoral amputees with osseointegrated fixation performing common activities of daily living
}

\author{
Winson Lee \\ University of Wollongong, ccwlee@uow.edu.au \\ Laurent A. Frossard \\ Queensland University of Technology \\ Kerstin Hagberg \\ Sahlgrenska University Hospital \\ Eva Haggstrom \\ Sahlgrenska University Hospital \\ Rickard Branemark \\ Sahlgrenska University Hospital
}

See next page for additional authors

Follow this and additional works at: https://ro.uow.edu.au/eispapers

Part of the Engineering Commons, and the Science and Technology Studies Commons

\footnotetext{
Research Online is the open access institutional repository for the University of Wollongong. For further information
} contact the UOW Library: research-pubs@uow.edu.au 


\title{
Kinetics of transfemoral amputees with osseointegrated fixation performing common activities of daily living
}

\begin{abstract}
Direct anchorage of a lower-limb prosthesis to the bone through an implanted fixation (osseointegration) has been suggested as an excellent alternative for amputees experiencing complications from use of a conventional socket-type prosthesis. However, an attempt needs to be made to optimize the mechanical design of the fixation and refine the rehabilitation program. Understanding the load applied on the fixation is a crucial step towards this goal. METHODS: The load applied on the osseointegrated fixation of nine transfemoral amputees was measured using a load transducer, when the amputees performed activities which included straight-line level walking, ascending and descending stairs and a ramp as well as walking around a circle. Force and moment patterns along each gait cycle, magnitudes and time of occurrence of the local extrema of the load, as well as impulses were analysed. FINDINGS: Managing a ramp and stairs, and walking around a circle did not produce a significant increase $(P>0.05)$ in load compared to straightline level walking. The patterns of the moment about the medio-lateral axis were different among the six activities which may reflect the different strategies used in controlling the prosthetic knee joint. INTERPRETATIONS: This study increases the understanding of biomechanics of bone-anchored osseointegrated prostheses. The loading data provided will be useful in designing the osseointegrated fixation to increase the fatigue life and to refine the rehabilitation protocol.
\end{abstract}

\section{Keywords}

fixation, performing, common, transfemoral, kinetics, amputees, living, osseointegrated, daily, activities

\section{Disciplines}

Engineering | Science and Technology Studies

\section{Publication Details}

Lee, W. C. C., Frossard, L. A., Hagberg, K., Haggstrom, E., Branemark, R., Evans, J. H. \& Pearcy, M. J. (2007). Kinetics of transfemoral amputees with osseointegrated fixation performing common activities of daily living. Clinical Biomechanics, 22 (6), 665-673.

\section{Authors}

Winson Lee, Laurent A. Frossard, Kerstin Hagberg, Eva Haggstrom, Rickard Branemark, John H. Evans, and Mark J. Pearcy 
Kinetics of Transfemoral Amputees with Osseointegrated Fixation Performing Common Activities of Daily Living

Revision based on the Editor's and Reviewers' comments Submitted to Clinical Biomechanics, Feb 2007

Winson C.C. Lee ${ }^{1,2}$ (PhD), Laurent A. Frossard ${ }^{1,2}$ (PhD), Kerstin Hagberg ${ }^{3}$ (RPT, PhD), Eva Haggstrom $^{4}$ (CPO), and Rickard Brånemark ${ }^{3}$ (MD, MSc, PhD), John H. Evans ${ }^{1,2}$ (PhD), Mark J. Pearcy ${ }^{1,2}$ (PhD)

${ }^{1}$ School of Engineering Systems, Queensland University of Technology, Brisbane, Australia

${ }^{2}$ Institute of Health \& Biomedical Innovation, Queensland University of Technology, Brisbane, Australia

${ }^{3}$ Centre of Orthopaedic Osseointegration, Sahlgrenska University Hospital, Goteborg, Sweden ${ }^{4}$ Department of Prosthetics and Orthotics, Sahlgrenska University Hospital, Goteborg, Sweden

Corresponding author and print request to:

Dr. Winson Lee

Institute of Health and Biomedical Innovation

Queensland University of Technology

Victoria Park Road

Kelvin Grove Qld 4059, AUSTRALIA

Phone: 61 (0)7 31386099

Fax: $61(0) 731386030$

Email: wc.lee@qut.edu.au 


\section{ABSTRACT}

Background: Direct anchorage of a lower-limb prosthesis to the bone through an implanted fixation (osseointegration) has been suggested as an excellent alternative for amputees experiencing complications from use of a conventional socket-type prosthesis. However, an attempt needs to be made to optimize the mechanical design of the fixation and refine the rehabilitation program. Understanding the load applied on the fixation is a crucial step towards this goal.

Methods: The load applied on the osseointegrated fixation of nine transfemoral amputees was measured using a load transducer, when the amputees performed activities which included straight-line level walking, ascending and descending stairs and a ramp as well as walking around a circle. Force and moment patterns along each gait cycle, magnitudes and time of occurrence of the local extrema of the load, as well as impulses were analysed.

Findings: Managing a ramp and stairs, and walking around a circle did not produce a significant increase $(P>0.05)$ in load compared to straight-line level walking. The patterns of the moment about the medio-lateral axis were different among the six activities which may reflect the different strategies used in controlling the prosthetic knee joint.

Interpretations: This study increases the understanding of biomechanics of bone-anchored osseointegrated prostheses. The loading data provided will be useful in designing the osseointegrated fixation to increase the fatigue life and to refine rehabilitation protocol.

Keywords: transfemoral amputation, prosthetics, osseointegration, transducer, activities of daily living. 


\section{INTRODUCTION}

The most common method of attaching a prosthesis to a residual limb is by means of a prosthetic socket, often with some suspensory devices to retain the socket when not loadbearing. Although this attachment method has been used for over a century, problems of pain in the residual limb and skin breakdown sometimes arise (Gallagher et al., 2001; Hagberg and Branemakr, 2001; Hagberg and Branemark, 2001; Mak et al., 2001). High pressure applied from the prosthetic socket to the soft tissue of a residual limb that is not adapted to tolerate load has been suggested as the cause of the pain and skin breakdown. In addition, some residual limbs are too short to support the use of a conventional socket.

In part to overcome these problems, a surgical technique (osseointegration) has been developed to allow a prosthesis to be directly anchored to the bone through a fixation based on a titanium implant. A coupling device (the abutment) is attached to the implant, while its distal end protrudes through the soft tissue to provide the attachment for the external prosthesis. In addition to alleviating the skin problems and residual limb pain (Sullivan et al., 2003), studies have also shown that amputees using transfemoral osseointegrated prostheses enjoy a greater range of hip motion and better sitting comfort compared to the socket-type (Hagberg et al., 2005). They can walk further and be more active than using a conventional prosthesis (Robinson et al., 2004; Sullivan et al., 2003), and can have improved sensory feedback (through 'osseoperception') (Branemark et al., 2001). External components of the prosthesis can be attached to and detached from the abutment easily and the alignment is faithfully preserved. To date, there are over 80 transfemoral amputees world-wide who have been fitted with the transfemoral osseointegrated fixation developed by Dr. R. Brånemark (Branemark et al., 2001). However, factors such as steroid medication or anti-tumour chemotherapy which may interfere with bone healing, heavy smoking or diabetes which may 
increase risk of bone sepsis, and body weight in excess of $100 \mathrm{~kg}$ are possibly contraindicate to the fitting of lower-limb osseointegrated prostheses (Robinson et al., 2004).

As with amputees using socket-type prostheses, those who use osseointegrated prostheses undergo a rehabilitation process, which involves incremental static loadings on the abutment to prepare the bone to tolerate forces transmitted from the implant when performing essential activities. Understanding the load experienced during various activities might help refine the rehabilitation process. Previous studies have also indicated certain gait deviations among transfemoral amputees in walking on level and uneven terrains (Jaegers et al., 1995; James and Oberg, 1973; Murray et al., 1983; Schmalz et al., 2007), in spite of the improved prosthetic knee joint designs in locking and bending mechanics. In addition, mechanical failures of the abutment sometimes occur after long use or as the result of excessively high magnitude load application usually induced by a fall (Sullivan et al., 2003). The abutment is designed to fail in order to protect the bone from overload, but attempts can be made to optimize the strength of the fixation and to develop safety devices to protect the fixation and the bone with the understanding of the loads developed during common daily activities. To refine the rehabilitation program as well as to develop the fixation system, safety devices and different prosthetic components to address the mechanical problems and improving walking ability, it is important to have a comprehensive understanding of the load applied on the fixation.

Over the past two decades, loadings applied at the distal end of prosthetic sockets have been studied (DiAngelo et al., 1989; Stephenson and Seedhom, 2002; Nietert et al., 1998; Berme et al., 1975; Frossard et al., 2003). The load has been calculated using inverse dynamics relying on the motion of the prosthesis captured by a motion analysis system and the ground reaction 
forces measured by a force plate (DiAngelo et al., 1989; Stephenson and Seedhom, 2002). The load can also be measured directly using appropriate load transducers (Berme et al., 1975; Nietert et al, 1998). Frossard and colleagues (Frossard et al., 2003) measured the direct load applied at the transfemoral socket end using a commercial load transducer mounted between the prosthetic knee joint and the socket, and suggested that direct load measurement could improve accuracy and allow measurement to be taken for unlimited walking steps. In addition, direct measurement allows loadings to be measured for any type of activity and on any terrain.

Although the application of such direct measurement technics to transfemoral amputees using osseointegrated prostheses has been reported (Frossard et al., 2001), the data were limited to one subject only. Comprehensive understanding of the load applied on osseointegrated fixation during level walking is important. It is also crucial to understand the load in various activities of daily living such as climbing stairs and walking inclines. Because of the loss of some musculature and joint mobility, functional demands may increase dramatically when performing daily activities. In addition, amputees may employ different loading strategies to help them manage different activities, all of which may pose a potential danger to the structural integrity of the fixation system and the bone.

The aim of this study is to use a direct measurement method to compare the load applied on the osseointegrated fixation of nine transfemoral amputees performing several activities of daily living including managing ramps, stairs and walking around a circle which are believed to be the most commonly performed activities during daily living. 


\section{METHODS}

\section{Participants and prostheses}

A total of two female and seven male unilateral transfemoral amputees fitted with osseointegrated fixation participated in this study. The demographic details of each subject are summarized in Table 1. All participants have been walking with the fixation for at least one year, and can walk 200m independently without additional walking aids. Load measurement took place in a clinical environment at Sahlgrenska University Hospital, Gothenburg, Sweden where the participants were recruited. Human research ethical approval was received from the Queensland University of Technology. Written consent was obtained from all participants.

Amputees were fitted with their regular prosthetic components, as presented in Table 1, with the load transducer substituted for the adaptor which connected the Rotasafe to the knee joint. Rotasafe is a safety device, based on a clutch, which prevents excessive torque on the abutment. A compromise was made for three participants who could not retain a Rotosafe due to the lack of space to fit the load transducer. The transducer was fitted by a prosthetist who replicated the usual alignment of the prosthesis for each amputee.

\section{Apparatus}

The technique used to measure the load is similar to the one described in previous studies (Frossard et al., 2003; Frossard et al., 2001). A six-channel load transducer (Model 45E15A; JR3 Inc., Woodland, USA) was used to measure directly the 3-dimensional forces and moments applied to the abutment. The transducer was mounted to customized plates that were 
positioned between the abutment and the prosthetic knee. The transducer was aligned so that its vertical axis was co-axial with the long (L) axis of the abutment and femur. The other axes corresponded to the anatomical antero-posterior (AP) and medio-lateral (ML) direction of the abutment as depicted in Figure 1. Forces acting along the AP, ML and L axes were denoted as $\mathrm{F}_{\mathrm{AP}}$ (anterior was positive), $\mathrm{F}_{\mathrm{ML}}$ (lateral was positive), and $\mathrm{F}_{\mathrm{L}}$ (compression was positive), respectively. Moments about the three axes were denoted as $\mathrm{M}_{\mathrm{AP}}$ (lateral rotation was positive), $\mathrm{M}_{\mathrm{ML}}$ (anterior rotation was positive) and $\mathrm{M}_{\mathrm{L}}$ (external rotation was positive), respectively. The maximum capacity was $2,273 \mathrm{~N}$ for $\mathrm{F}_{\mathrm{L}}, 1,136 \mathrm{~N}$ for $\mathrm{F}_{\mathrm{AP}}$ and $\mathrm{F}_{\mathrm{ML}}$, and $130 \mathrm{Nm}$ for moments about the three axes. Accuracy was $0.1 \%$ of the maximum capacity. Each channel was sampled at $200 \mathrm{~Hz}$. A wireless modem (Ricochet Model 21062; Metricom Inc., Los Gatos, USA) was used to transmit data from the transducer to a nearby laptop computer.

\section{Protocol}

Approximately 15 minutes of practice with the instrumented prosthetic leg was allowed before load measurement to ensure subject confidence and comfort. Then, the participants were asked to perform each of the activities including: straight-line level walking; walking upstairs, downstairs, upslope, and downslope; and walking along a circle. Detailed descriptions of each activity are shown in Table 2. Load data was measured for at least five steps of the prosthetic limb for each activity. The amputees were required to walk and manage the stairs and slope at a self-selected, comfortable speed. The order of each activity was randomized. Finally, the prosthesis was detached from the residuum to enable a one-minute recording without load applied on the transducer for calibration purposes.

\section{Data processing}


The raw force and moment data was imported and processed by a customized Matlab software program (The MathWorks Inc., MA, USA). The load data was offset according to the magnitude of the load recorded during unloaded conditions. The first and last strides recorded for each trial were also removed in order to avoid the initiation and termination of walking. The patterns of the three-dimensional forces and moments for each gait cycle were analysed. The heel contact and toe-off time was determined according to the curve of the long-axis force. A gait cycle was defined as the period between two consecutive heel contacts.

The magnitude of local extrema of the three components of forces and moments presented in Figure 2 were determined for each step of the prosthetic limb. Resultant forces $\left(\mathrm{F}_{\mathrm{r}}\right)$ were calculated by the vector sum of $\mathrm{F}_{\mathrm{AP}}, \mathrm{F}_{\mathrm{ML}}$ and $\mathrm{F}_{\mathrm{L}}$. The time of occurrence (expressed in percentage of stance phase time) as well as the magnitude (expressed in percentage of body weight) of the local extrema of $F_{r}$ were identified. Impulse ( $I_{A P}, I_{M L}, I_{L}$ and $I_{R}$ ) for each step of the prosthetic limb was calculated by using the conventional trapezoid method to integrate the area under the force-time curves $\left(\mathrm{F}_{\mathrm{AP}}, \mathrm{F}_{\mathrm{ML}}, \mathrm{F}_{\mathrm{L}}\right.$ and $\mathrm{F}_{\mathrm{r}}$ ). Each parameter (the local extrema, time of occurrence and impulse) was averaged across steps for each subject. To discuss the differences in loading strategies among various activities of daily living, the means and standard deviations of each parameter across subjects were computed for each activity. Statistical analyses were performed in SPSS statistical software (LEAD technologies, Inc.). Differences among the activities were determined by repeated measures analysis of variance (ANOVA). A post-hoc Tukey's test was used to identify the significant difference. A significance level of $P<0.05$ was used.

\section{RESULTS}




\section{Patterns of forces and moments}

Figure 2 shows the typical patterns of forces and moments in straight-line level walking. It can be seen that although the three loading axes (AP, ML, L) were fixed relative to the limb during ambulation, the three components of forces followed a pattern that was similar to the ground reaction forces obtained with a fixed force-plate (Perry, 1992; Zahedi et al., 1987). As expected, $F_{L}$ was the largest in magnitude among the three components of forces and presented two peaks and a valley. Small plateaus were found immediately before the first peak of the curve in a few subjects, which may be explained by a sense of insecurity or discomfort. During level walking, the abutment experienced some posterior braking forces at the early stance phase, and anterior propulsive forces at the late stance phase, and consistently experienced some lateral forces throughout the entire stance phase of the gait. Lateral rotational moment was consistently experienced during the stance phase of the gait. Anterior rotational moment was experienced during the mid-stance phase, and posterior rotational moment at the late-stance phase related to unlocking of the prosthetic knee joint was experienced when performing level walking. Due to the traction created by gravity acting on the mass of the prosthesis which was located below the transducer, the forces and moments had small magnitudes during the swing phase. All subjects demonstrated similar patterns of forces and moments for level walking, except for $M_{L}$ which showed inconsistent patterns among participants (Figure 3).

When performing the other activities of daily living, the patterns of forces and moments were close to those of level walking as described above. However, there were exceptions for $\mathrm{F}_{\mathrm{AP}}$, $\mathrm{M}_{\mathrm{L}}$, and $\mathrm{M}_{\mathrm{ML}}$. Figures $4 \mathrm{a}$ and $4 \mathrm{~b}$ show $\mathrm{F}_{\mathrm{AP}}$ along a gait cycle when the majority of the subjects walked upstairs and downstairs. Unlike level walking with some posterior forces 
exerted at the abutment at the early stance phase and anterior forces at the late stance phase, the abutments of seven subjects experienced posterior forces most of the time at the stance phase when they walked downstairs. When walking upstairs, the abutment of six subjects experienced anterior forces during the entire stance phase. The $\mathrm{F}_{\mathrm{AP}}$ patterns of the remaining subjects are displayed in Figures 4c and 4d, which show entirely different curve patterns. In calculating the local extrema of $F_{A P}$, those remaining subjects were excluded. Patterns of $F_{A P}$ for walking inclines and around a circle follow those for straight-line level walking. All subjects demonstrated inconsistent $\mathrm{M}_{\mathrm{L}}$ patterns among the six activities depicted in Figure 5. Figures 6a-d display the different patterns of $\mathrm{M}_{\mathrm{ML}}$ for all subjects among the four activities: ascending and descending stairs and a ramp. Walking upslope and upstairs produced an average anterior rotational moment of $17 \mathrm{Nm}$ and $10 \mathrm{Nm}$ respectively, while walking downslope and downstairs did not produce a prominent peak anterior rotation moment (Figure 6). Walking around a circle produced similar $\mathrm{M}_{\mathrm{ML}}$ patterns to level walking along a straight line.

\section{Local extrema}

A total of ten local extrema for the three components of forces and moments were studied, which represented the key features of the curve plotting force/moment data against time as presented in Figure 2. The local extrema were the turning points of the curves which presented the highest absolute magnitude of loads. Two local extrema were identified for the maximum anterior $\left(\mathrm{F}_{\mathrm{AP}+}\right)$ and posterior $\left(\mathrm{F}_{\mathrm{AP}-}\right)$ forces, one for the maximum lateral force $\left(\mathrm{F}_{\mathrm{ML}^{+}}\right)$, and two peaks for the axial force $\left(\mathrm{F}_{\mathrm{L} 1}\right.$ and $\left.\mathrm{F}_{\mathrm{L} 2}\right)$. One local extrema was identified for the maximum lateral rotational moment $\left(\mathrm{M}_{\mathrm{AP}+}\right)$, two for the maximum anterior $\left(\mathrm{M}_{\mathrm{ML}+}\right)$ and posterior $\left(\mathrm{M}_{\mathrm{ML}-}\right)$ rotational moments and two local extrema were identified for the peak external $\left(\mathrm{M}_{\mathrm{L}+}\right)$ and internal $\left(\mathrm{M}_{\mathrm{L}-}\right)$ rotational moments. In addition, the magnitudes of the two 
peaks $\left(\mathrm{F}_{\mathrm{r} 1}\right.$ and $\left.\mathrm{F}_{\mathrm{r} 2}\right)$ and the time of occurrence of the two peaks $\left(\mathrm{T}_{\mathrm{FR} 1}\right.$ and $\left.\mathrm{T}_{\mathrm{FR} 2}\right)$ were identified.

Table 3 shows the mean and standard deviation across subjects of each local extrema in six different activities. There was no statistical difference among activities in each local extrema of the three components of forces and moments. As far as the body-weight normalized resultant forces are concerned as presented in Table 4, it was found that the $F_{r 1}$ in walking upstairs [101\% (SD 14\%) body weight] was statistically higher than in walking downstairs [78\% (SD 12\%) body weight]. Meanwhile, the $\mathrm{T}_{\mathrm{FR} 2}$ in walking downstairs [56\% (SD 11\%) stance phase] was statistically earlier than other activities except walking downslope. The $\mathrm{T}_{\mathrm{FR} 1}$ in walking downstairs [26\% (SD 33\%) stance phase], in addition, appeared statistically earlier than walking upstairs [39\% (SD 8\%) stance phase]. Time of occurrence of local extrema in each particular component of force and moment was not computed because of the highly inconsistent patterns in some activities.

\section{Impulses}

The overall loading of the prosthesis over the support phase represented by the impulse is provided in Table 5. As expected, the impulse produced in long axis $\left(\mathrm{I}_{\mathrm{L}}\right)$ was the largest in magnitude among the three axes. $\mathrm{I}_{\mathrm{AP}}$ in walking upslope was statistically higher than that of walking downslope and downstairs, while $I_{L}$ and $I_{R}$ in walking downstairs was statistically lower than other activities except walking down the slope.

\section{DISCUSSION}


Conventionally, the load experienced by prosthetic components, including implants in the lower limbs, can be estimated using inverse dynamics methods which are based on the motion of the limb and the ground reaction forces (DiAngelo et al., 1989; Stephenson and Seedhom, 2002). The drawbacks of this method are that only one or two steps of walking can usually be measured, force-plate targeting can produce 'un-natural' gait (Wearing et al., 2001), and accurate determination of inertia of natural and prosthetic limb segments is needed. In addition, loads cannot be measured easily using force plates when walking on uneven terrain. This study used a portable recording system based on a load transducer and a wireless modem. This allowed direct measurement of load applied to the abutment. In addition, the wireless system allowed the true loading to be measured in different environments, and subjects could walk unimpeded when they performed the various activities.

The main objective of this study was to examine the differences in load applied on osseointegrated fixation during various activities of daily living. If level straight-line walking is considered to be the baseline, it was found that the other five activities which were believed to be more physically demanding did not produce any statistically significant increase in loading when compared to the baseline. This may imply that these five activities would not induce higher risk to the structural integrity of the fixation system. Impulses represented the utilisation of the prosthesis. $\mathrm{I}_{\mathrm{L}}$ in walking downstairs was statistically lower than in straightline walking, but it was also statistically lower than walking upslope, upstairs and around a circle.

There was no statistical difference in local extrema identified in the three components of forces and moments between every pair of activities. Although there were large differences in some cases, for instance, $\mathrm{F}_{\mathrm{AP}}$ in walking downstairs was $47 \%$ higher than the average of all 
the other activities, a statistical difference was not reached because of the large standard deviations across subjects. Some statistical differences were found in the magnitude and the time of occurrence of peak resultant forces. $F_{r 1}$ in walking downstairs was on average the lowest among all activities and was statistically lower than in walking upstairs. In addition, $\mathrm{T}_{\mathrm{FR} 2}$ in walking downstairs and downslope were statistically earlier than some other activities, while $\mathrm{T}_{\mathrm{FR} 1}$ in walking downstairs was statistically earlier than in walking upslope. The earlier peaks as well as lower magnitude of $\mathrm{F}_{\mathrm{r} 1}$ are likely to be due to the rapid forward progression of the prosthetic limb, resulting from the lack of plantar flexion and active knee flexion of the prosthetic joints, which are important in maintaining stability when descending from a step or a ramp. This also explains the significant reduction of impulses in walking downstairs. In addition, because of the lack of active motion of the joints, amputees tend to roll the prosthetic foot over the step edges when managing stair descent as reported for conventional transfemoral amputees (Schmalz et al., 2007).

Similar patterns of forces and moments were seen in the six different activities, except for $\mathrm{F}_{\mathrm{AP}}, \mathrm{M}_{\mathrm{L}}$ and $\mathrm{M}_{\mathrm{ML}}$. Rotational moment $\left(\mathrm{M}_{\mathrm{L}}\right)$ was inconsistent among subjects and activities. The maximum absolute value of external and internal rotational moment fell within a narrow range between $3.0 \mathrm{Nm}$ to $6.3 \mathrm{Nm}$ among the six activities. This could have implications in the minimal torque required to tighten the abutment to the implant, as well as threshold value for the Rotasafe rational protective devices. The variations in the patterns of $F_{A P}$ and $M_{M L}$ could suggest that amputees use different strategies in prosthetic knee joint control when they manage different activities. Walking upslope and upstairs produced some anterior rotational moment during stance phase. Walking downslope and downstairs, on the other hand, did not produce a prominent peak anterior rotation moment (Figure 5), which indicates the line of action of the ground reaction force was always kept behind the knee joint. There was a peak 
posterior rotational moment at the late stance phase of the gait when the subjects performed level walking, managing slope, and walking around a circle. This could be explained by the effort of initiating knee flexion in order to provide foot clearance during the swing phase.

Various strategies of prosthetic knee control might explain the different loading recorded in different activities. A good control of the prosthetic knee is critical for a smooth ambulation and there are different prosthetic knees in the market that employ various control mechanisms in giving motion and stability to the knee. The differences in loading may also be explained by the different walking patterns. For example, rolling the prosthetic foot over the edge of the step may explain the reduction of loads. Prosthetic alignment, which refers to the special position of the prosthetic foot relative to the residual limb, is also important. Variation in alignment can change the load transfer biomechanics as well as walking ability. In order to aid in precise explanation of the load, control of the prosthetic knee and alignment, future studies can collect simultaneous kinetic and kinematic data to determine body motion, knee joint angle and loading. Studies can also be performed to investigate the effect of different knee mechanisms and alignment on gait.

This study focuses on the loading applied on the fixation system which will be helpful in the future mechanical design of the system and refining of the rehabilitation process. Future studies will perform experimental structural test and computational stress analyses to investigate the stress/strain distribution at the bone-implant interface and the entire fixation system and estimate the fatigue life using the existing load data.

\section{CONCLUSIONS}


This study measured and compared the load acting on the fixation of nine transfemoral amputees fitted with osseointegrated fixation performing six different activities of daily living. The magnitudes of local extrema as well as the curve patterns of each component of forces and moments were revealed. Results suggested that managing ramp and stairs, and walking around a circle did not produce a significant increase in load compared to straightline level walking. Results also suggested that different strategies were used to control the prosthetic knee joint for different activities. Future studies will attempt to utilize this load data to optimize the fixation design as well as to refine the rehabilitation process, and to collect kinematic data to produce full explanation of the load data.

\section{ACKNOWLEDGEMENT}

The authors would like to express their gratitude to members of the School of Engineering Systems and Institute of Health \& Biomedical Innovation, particularly Dr James Smeathers, for their valuable contribution and feedback during the writing of this manuscript. This study was partially funded by ARC Discovery Project (DP0345667), ARC Linkage (LP0455481), QUT Strategic Link with Industry and IHBI Medical Device Domain grants. 


\section{APPENDIX}

\section{Abbreviations list:}

$\mathrm{F}_{\mathrm{AP}}$ : Antero-posterior force

$\mathrm{F}_{\mathrm{ML}}$ : Medio-lateral force

$\mathrm{F}_{\mathrm{L}}$ : Long-axis (of residual femur) force

$\mathrm{F}_{\mathrm{r}}$ : Resultant force

$\mathrm{M}_{\mathrm{AP}}$ : Moment about the antero-posterior axis

$\mathrm{M}_{\mathrm{ML}}$ : Moment about the medio-lateral axis

$\mathrm{M}_{\mathrm{L}}$ : Moment about the long-axis

$\mathrm{F}_{\mathrm{AP}^{-}}, \mathrm{F}_{\mathrm{AP}+}$ : The most positive and negative values of $\mathrm{F}_{\mathrm{AP}}$

$\mathrm{F}_{\mathrm{ML}+}$ : The most positive value of $\mathrm{F}_{\mathrm{ML}}$

$\mathrm{F}_{\mathrm{L} 1}, \mathrm{~F}_{\mathrm{L} 2}$ : The two peaks of $\mathrm{F}_{\mathrm{L}}$

$\mathrm{M}_{\mathrm{AP}+}$ : The most positive value of the $\mathrm{M}_{\mathrm{AP}}$

$\mathrm{M}_{\mathrm{ML}+}, \mathrm{M}_{\mathrm{ML}-\mathrm{:}}$ The most positive and negative value of the $\mathrm{M}_{\mathrm{ML}}$

$\mathrm{M}_{\mathrm{L}+}, \mathrm{M}_{\mathrm{L}-}$ : The most positive and negative value of the $\mathrm{M}_{\mathrm{L}}$

$F_{r 1}, F_{r 2}$ : The two peaks of $F_{r}$

$\mathrm{T}_{\mathrm{FR} 1}, \mathrm{~T}_{\mathrm{FR} 2}$ : Time of occurrence of $\mathrm{F}_{\mathrm{r} 1}$ and $\mathrm{F}_{\mathrm{r} 2}$

$\mathrm{I}_{\mathrm{AP}}$ : Impulse of $\mathrm{F}_{\mathrm{AP}}$ (integrated the area under the force-time curve)

$\mathrm{I}_{\mathrm{ML}}$ : Impulse of $\mathrm{F}_{\mathrm{ML}}$ (integrated the area under the force-time curve)

$\mathrm{I}_{\mathrm{L}}$ : Impulse of $\mathrm{F}_{\mathrm{L}}$ (integrated the area under the force-time curve)

$I_{R}$ : Impulse of $F_{R}$ (integrated the area under the force-time curve) 


\section{REFERENCES}

Berme, N., Lawes, P., Solomonidis, S., Paul, J.P., 1975. A shorter pylon transducer for measurement of prosthetic forces and moments during amputee gait. Engineering in Medicin 4, 6-8.

Branemakr, R., Branemark, P.I., Rydevik, B., Myers, R., 2001. Osseointegration in skeletal reconstruction and rehabilitation: A review. Journal of Rehabilitation Research \& Development 38, 175-81.

DiAngelo, D.J., Winter, D.A., Ghista, D.N., Newcombe, W.R., 1989. Performance assessment of the Terry Fox jogging prosthesis for above-knee amputees. Journal of Biomechanics 22, 543-548.

Frossard, L., Beck, J., Dillon, M., Chappell, M., Evans, J.H., 2003. Development and preliminary testing of a device for the direct measurement of forces and moments in the prosthetic limb of transfemoral amputees during activities of daily living. Journal of Prosthetics and Orthotics 15, 135-142.

Frossard, L., Beck, J., Dillon, M., Evans, J., 2001. Comparison between the forces and moments applied on the residium of above-knee amputees during daily life activities and walking. Proceedings of Xth International Society of Prosthetics and Orthotics World Congress. Glasgow, Scottland.

Gallagher, P., Allen, D., MacLachlan, M.I., 2001. Phantom limb pain and residual limb pain following lower limb amputation: a descriptive analysis. Disability and Rehabilitation 26, 522-530.

Hagberg, K., Branemark, R., 2001. Consequences of non-vascular trans-femoral amputation: a survey of quality of life, prosthetic use and problems. Prosthetics and Orthotics International 25, 186-194.

Hagberg, K., Haggstrom, E., Uden, M., Branemark, R., 2005. Socket versus bone-anchored trans-femoral prostheses: hip range of motion and sitting comfort. Prosthetics and Orthotics International 25, 186-194.

Jaegers, S.M.H.J., Arendzen, J.H., de Jongh, H.J., 1995. Prosthetic gait of unilateral transfemoral amputees: a kinematic study. Archives of Physical Medicine and Rehabilitation 76, 736-743.

James, U., Oberg, K., 1973. Prosthetic gait pattern in unilateral above-knee amputees. Scandinavian Journal of Rehabilitation and Medicine 5, 35-50.

Mak, A., Zhang, M., Boone, D., 2001. State-of-the-art research in lower-limb prosthetic biomechanics-socket interface: A review. Journal of Rehabilitation Research \& Development 28, 161-74. 
Murray, M.P., Mollinger, L.A., Sepic, S.B., Gardner, G.M., 1983. Gait patterns in above-knee amputee patients: hydraulic swing control vs constant-friction knee components. Archives of Physical Medicine and Rehabilitation 64, 339-45.

Nietert, M., Englisch, N., Kreil, P, Alba-Lopez, G., 1998. Loads in hip disarticulation prostheses during normal daily use. Prosthetics and Orthotics International 22, 199-215.

Perry, J., 1992. gait analysis: normal and pathological function: Thorofare, N.J.: SLACK.

Robinson, K.P., Branemark, R., Ward, D., 2004. Future developments: osseointegration in transfemoral amputees' in Smith, D.G., Michael, J.w., Bowker, J.H. (eds.) Atlas of Amputations and Limb Deficiencies: Surgical, Prosthetic and Rehabilitation Principles: America Academy of Orthopaedic Surgeons.

Schmalz, T., Blumentritt, S., Marx, B., 2007. Biomechanical analysis of stair ambulation in lower limb amputees. Gait \& Posture 25, 267-78.

Stephenson, P., Seedhom, B.B., 2002. Estimation of forces at the interface between an artificial limb and an implant directly fixed into the femur in above-knee amputees. Journal of Orthopaedic Science 7, 192-297.

Sullivan, J., Uden, M., Robinson, K., Sooriakumaran, S., 2003. Rehabilitation of the transfemoral amputee with an osseointegrated prosthesis: the United Kingdom experience. Prosthetics and Orthotics International 27, 114-120.

Wearing, S.c., Urry, S.r., Smeathers, J.E., 2001 Ground reaction forces at discrete sites of the foot derived from pressure plate measurements. Foot and Ankle International 22, 653-61.

Zahedi, M.S., Spence, W.D., Solomonidis, S.E., Paul, J.P., 1987. Repeatability of kinetic measurements in gait studies in gait studies of the lower limb amputee. Prosthetics and Orthotics International 11, 55-64. 
Table 1. Subject characteristics. ("The total mass includes body mass plus the mass of the instrumented prosthesis)

\begin{tabular}{|c|c|c|c|c|c|c|c|c|c|}
\hline $\begin{array}{l}\text { Subject } \\
\text { number }\end{array}$ & $\begin{array}{c}\text { Gender } \\
(\mathrm{M} / \mathrm{F})\end{array}$ & $\begin{array}{c}\text { Age } \\
\text { (years) }\end{array}$ & $\begin{array}{c}\text { Height } \\
\text { (m) }\end{array}$ & $\begin{array}{c}\text { Total } \\
\text { mass } \\
\text { (kg) }\end{array}$ & $\begin{array}{c}\text { Side of } \\
\text { amputation } \\
(\mathrm{R} / \mathrm{L})\end{array}$ & Footwear & $\begin{array}{l}\text { Prosthetic } \\
\text { foot }\end{array}$ & $\begin{array}{c}\text { Prosthetic } \\
\text { knee }\end{array}$ & Rotasafe \\
\hline 1 & $F$ & 57 & 1.63 & 61.1 & $\mathrm{R}$ & Sandals & $\begin{array}{c}\text { Total } \\
\text { concept }\end{array}$ & Total knee & Yes \\
\hline 2 & $\mathrm{M}$ & 50 & 1.81 & 74.3 & $\mathrm{~L}$ & Sandals & TruStep & Total knee & No \\
\hline 3 & M & 59 & 1.89 & 87.1 & $\mathrm{R}$ & $\begin{array}{c}\text { Leather } \\
\text { shoes }\end{array}$ & TruStep & Total knee & No \\
\hline 4 & $\mathrm{~F}$ & 49 & 1.58 & 53.3 & $\mathrm{R}$ & Sandals & $\begin{array}{c}\text { Total } \\
\text { concept }\end{array}$ & Total knee & Yes \\
\hline 5 & $\mathrm{M}$ & 41 & 1.77 & 96.6 & $\mathrm{R}$ & $\begin{array}{l}\text { Running } \\
\text { shoes }\end{array}$ & C-Walk & Total knee & No \\
\hline 6 & $\mathrm{M}$ & 26 & 1.78 & 90 & $\mathrm{R}$ & $\begin{array}{c}\text { Leather } \\
\text { shoes }\end{array}$ & $\begin{array}{c}\text { Carbon } \\
\text { Copy }\end{array}$ & C-leg & Yes \\
\hline 7 & $\mathrm{M}$ & 46 & 1.99 & 99.5 & $\mathrm{~L}$ & Sandals & C-Walk & Total knee & Yes \\
\hline 8 & $\mathrm{M}$ & 50 & 1.82 & 99.8 & $\mathrm{R}$ & $\begin{array}{c}\text { Leather } \\
\text { shoes }\end{array}$ & Flex Foot & GaitMaster & Yes \\
\hline 9 & $\mathrm{M}$ & 45 & 1.72 & 80.4 & $\mathrm{R}$ & $\begin{array}{c}\text { Running } \\
\text { shoes }\end{array}$ & TruStep & Total knee & Yes \\
\hline \multicolumn{2}{|c|}{ Mean } & 47 & 1.78 & 82.5 & & & & & \\
\hline \multicolumn{2}{|c|}{ Standard deviation } & 9.7 & 0.12 & 16.8 & & & & & \\
\hline
\end{tabular}

Table 2. Descriptions of the 6 various activities performed during direct measurement of load.

\begin{tabular}{|l|l|}
\hline \multicolumn{1}{|c|}{ Activities } & \multicolumn{1}{c|}{ Descriptions } \\
\hline Level walking & Level walking along a level, straight-line walkway \\
\hline Downslope & Descending a 6.5 degrees of slope \\
\hline Upslope & Ascending a 6.5 degrees of slope \\
\hline Downstairs & Descending stairs of $30 \mathrm{~cm}$ height x $34 \mathrm{~cm}$ deep \\
\hline Upstairs & Ascending stairs of $30 \mathrm{~cm}$ height $\mathrm{x} 34 \mathrm{~cm}$ deep \\
\hline Circle & Level walking around a circle of $2 \mathrm{~m}$ diameter with the prosthetic leg outside \\
\hline
\end{tabular}


Table 3. Mean and standard deviation (in bracket) across subjects of the nine local extrema. No statistical differences were found in those local extrema. (A “-“ indicates that there were no consistent peaks/valleies in that activity)

\begin{tabular}{c|cccccc}
\hline & Walking & Downslope & Upslope & Downstairs & Upstairs & Circle \\
\hline $\mathbf{F}_{\text {AP- }}(\mathbf{N})$ & $-74(36)$ & $-93(44)$ & $-53(34)$ & $-137(98)$ & - & $-69(29)$ \\
$\mathbf{F}_{\text {AP+ }} \mathbf{( N )}$ & $101(19)$ & $87(29)$ & $90(25)$ & - & $74(20)$ & $84(27)$ \\
$\mathbf{F}_{\mathbf{M L +}} \mathbf{( N )}$ & $89(35)$ & $79(22)$ & $93(39)$ & $53(14)$ & $76(30)$ & $93(34)$ \\
$\mathbf{F}_{\mathbf{L 1}} \mathbf{( N )}$ & $671(139)$ & $699(149)$ & $697(153)$ & $587(157)$ & $769(171)$ & $706(165)$ \\
$\mathbf{F}_{\mathbf{L} 2}(\mathbf{N})$ & $675(138)$ & $660(146)$ & $704(144)$ & $649(112)$ & $715(170)$ & $703(148)$ \\
$\mathbf{M}_{\mathbf{A P +}} \mathbf{( N m )}$ & $21(10)$ & $25(9)$ & $22(8)$ & $18(8)$ & $19(8)$ & $27(9)$ \\
$\mathbf{M}_{\mathbf{M L +}} \mathbf{( N m )}$ & $9(10)$ & - & $17(12)$ & - & $10(14)$ & $11(11)$ \\
$\mathbf{M}_{\mathbf{M L}-} \mathbf{( N m )}$ & $-20(9)$ & $-30(20)$ & $-20(9)$ & - & - & $-18(6)$ \\
$\mathbf{M}_{\mathbf{L}+} \mathbf{( N m )}$ & $3.7(1.2)$ & $5.3(2.7)$ & $3.2(1.7)$ & $5.3(3.6)$ & $3.0(1.1)$ & $3.8(1.7)$ \\
$\mathbf{M}_{\mathbf{L}-} \mathbf{( N m )}$ & $5.0(2.0)$ & $-3.8(1.3)$ & $-6.3(2.5)$ & $-3.5(1.0)$ & $-3.7(1.2)$ & $-5.4(1.2)$ \\
\hline
\end{tabular}

Table 4. Mean and standard deviation (in bracket) across subjects of the peak resultant forces

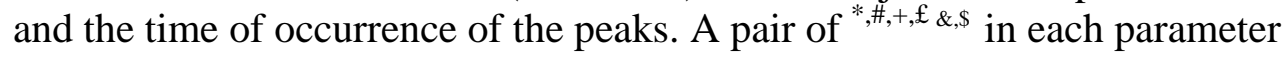
represents a statistical difference.

\begin{tabular}{|c|c|c|c|c|c|c|}
\hline 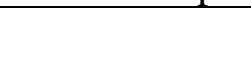 & Walking & Downslope & Upslope & Downstairs & Upstairs & Circle \\
\hline$F_{r 1}(\% B W)$ & 89 (6) & $89(8)$ & $91(5)$ & ${ }^{*} 78(20)$ & "101 (14) & $91(6)$ \\
\hline$F_{r 2}(\% B W)$ & 93 (9) & $86(7)$ & $94(8)$ & 85 (16) & $94(7)$ & 93 (6) \\
\hline $\mathrm{T}_{\mathrm{FR} 1}(\% \mathrm{SP})$ & $32(8)$ & $30(6)$ & *39 (8) & *26 (11) & $30(6)$ & $34(7)$ \\
\hline $\mathbf{T}_{\mathrm{FR2}}(\% \mathrm{SP})$ & *70 (3) & ${ }^{\&, \$} 63(8)$ & $\sharp, \& 72$ (4) & ${ }^{*, \#,+, £ 56(11)}$ & +,\$79 (3) & ${ }^{5} 70(4)$ \\
\hline
\end{tabular}

Table 5. Mean and standard deviation (in bracket) across subjects of impulses. A pair of ${ }^{*, \#,+, \varepsilon}$ in each parameter represents a statistical difference.

\begin{tabular}{|c|c|c|c|c|c|c|}
\hline & Walking & Downslope & Upslope & Downstairs & Upstairs & Circle \\
\hline $\mathrm{I}_{\mathrm{AP}}(\mathrm{Ns})$ & $108(37)$ & *75 (38) & *,\#130 (39) & ${ }^{\#} 67$ (33) & $104(35)$ & $113(33)$ \\
\hline $\mathbf{I}_{\mathrm{ML}}$ (Ns) & $58(41)$ & $51(36)$ & $65(47)$ & $42(27)$ & $54(38)$ & $62(42)$ \\
\hline $\mathbf{I}_{\mathrm{L}}(\mathrm{Ns})$ & ${ }^{*} 363$ (76) & 332 (56) & \#385 (79) & *,\#,+,£256 (31) & +367 (69) & ${ }^{£} 388(79)$ \\
\hline $\mathbf{I}_{\mathrm{R}}(\mathrm{Ns})$ & ${ }^{*} 386$ (81) & 348 (59) & \#415 (85) & *,\#,+,£271 (35) & +388 (72) & ${ }^{\mathrm{E}} 411$ (82) \\
\hline
\end{tabular}



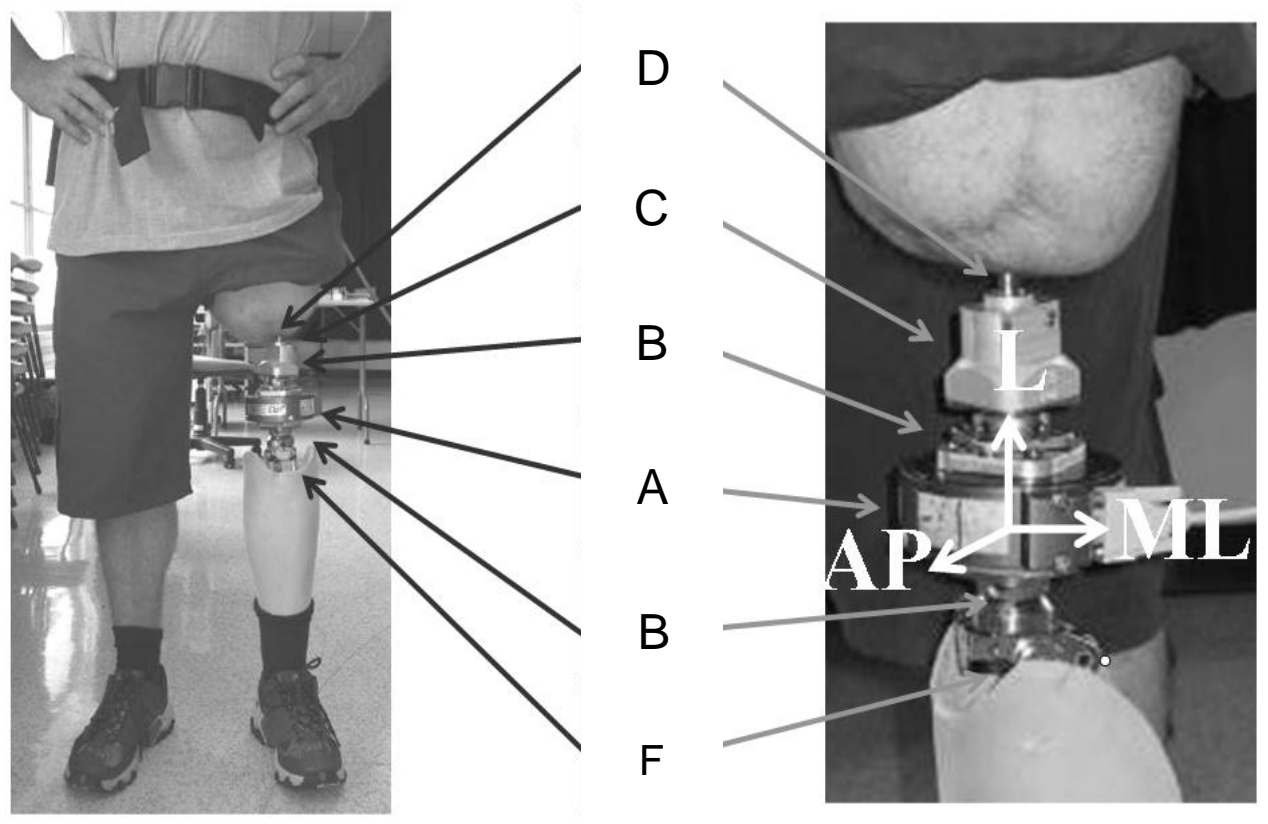

Figure 1. Example of a typical prosthetic leg setup used to directly measure the forces and moments applied on the fixation of transfemoral amputee (left: front view, right: side view). A commercial transducer (A) was mounted to specially designed plates (B) that were positioned between the adaptor (C) connected to the fixation (D) and the knee mechanism (F). 


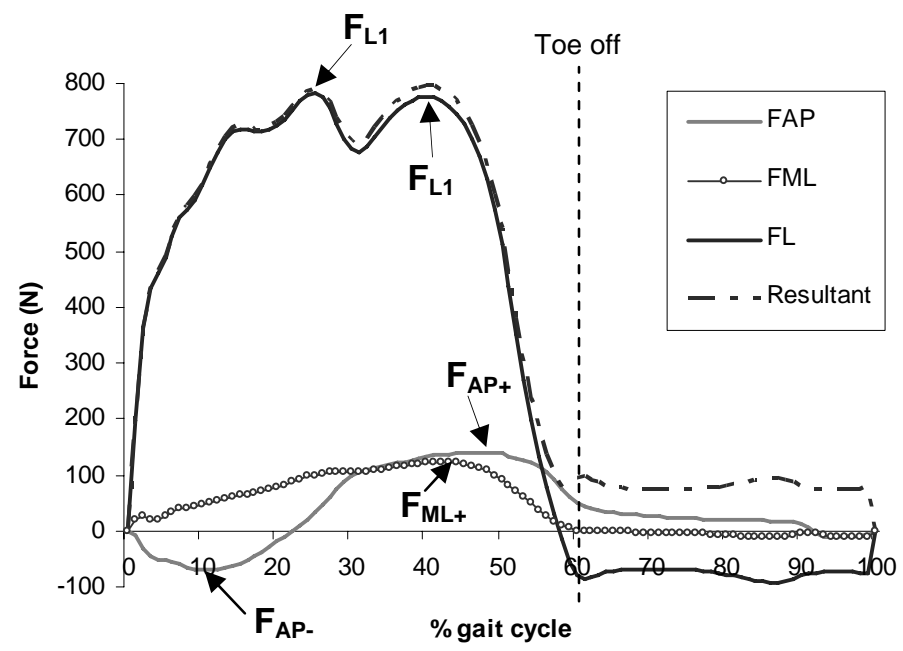

(a)

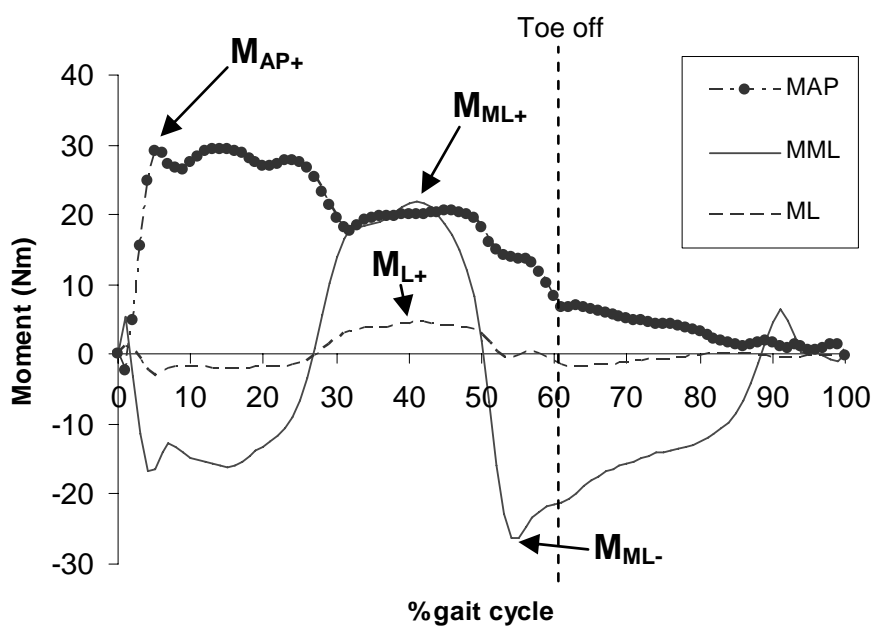

(b)

Figure 2. The local extrema and typical patterns of (a) forces and (b) moments along the anteroposterior (AP), mediolateral (ML), and long axis (L) axes of subject 1 performing straight-line level walking. 


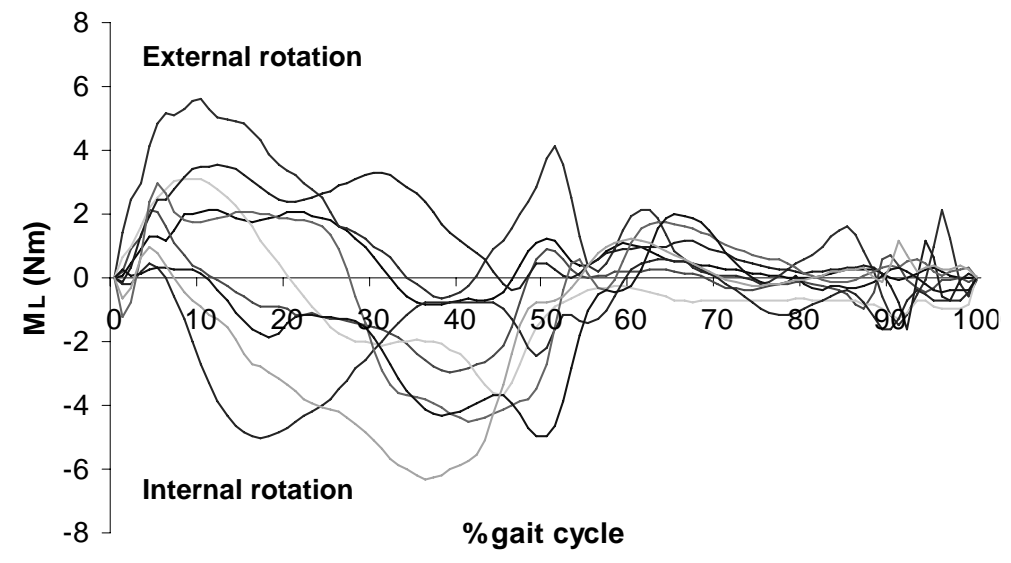

Figure 3. External/internal rotational moment $\left(\mathrm{M}_{\mathrm{L}}\right)$ for all subjects performing straight-line level walking. 


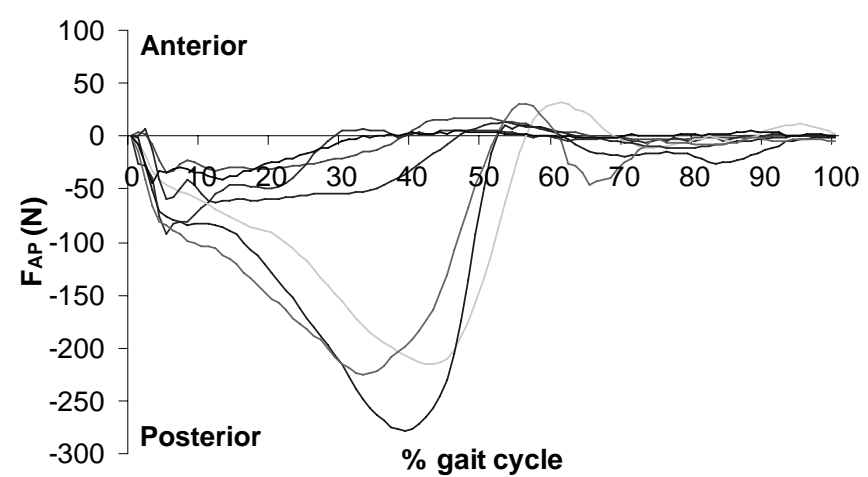

(a) Downstairs, $\mathrm{n}=7$

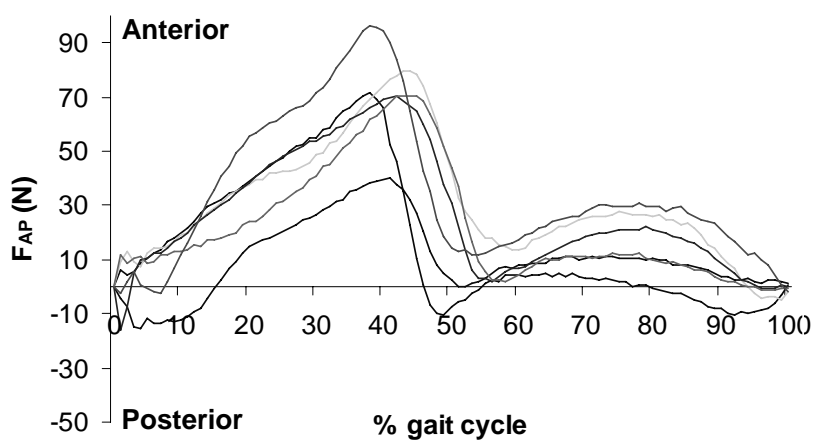

(b) Upstairs, $n=6$

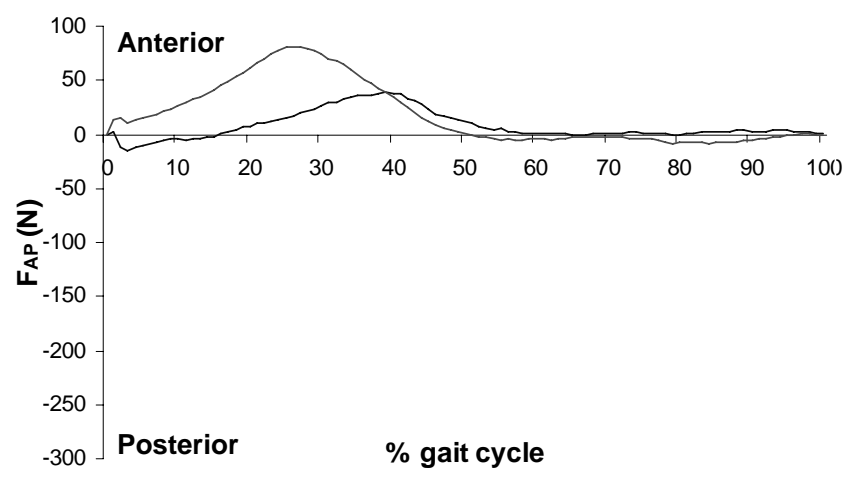

(c) Downstairs, $\mathrm{n}=2$

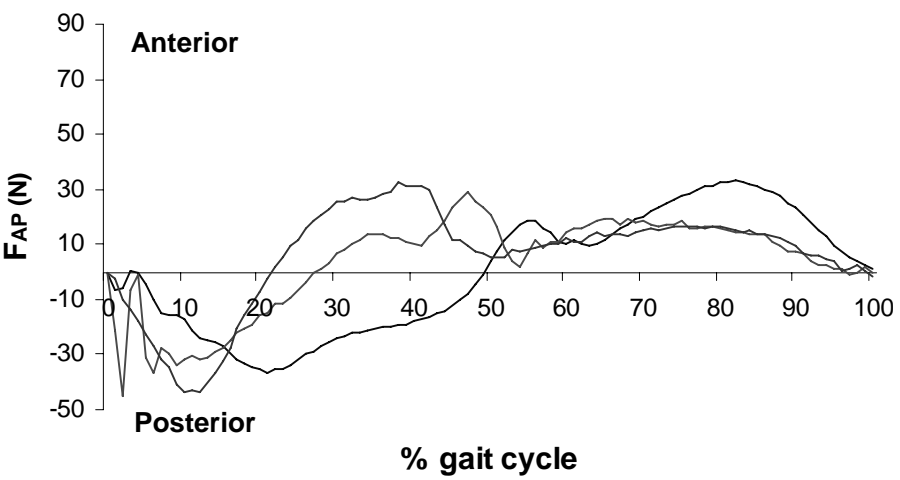

(d) Upstairs, $n=3$

Figure 4. Anteroposterior force for (a) seven subjects walking downstairs, and (b) six subjects walking upstairs. The remaining subjects are shown in (c) walking downstairs, and (d) walking upstairs, which showed different curve patterns from the majority of the amputees. 


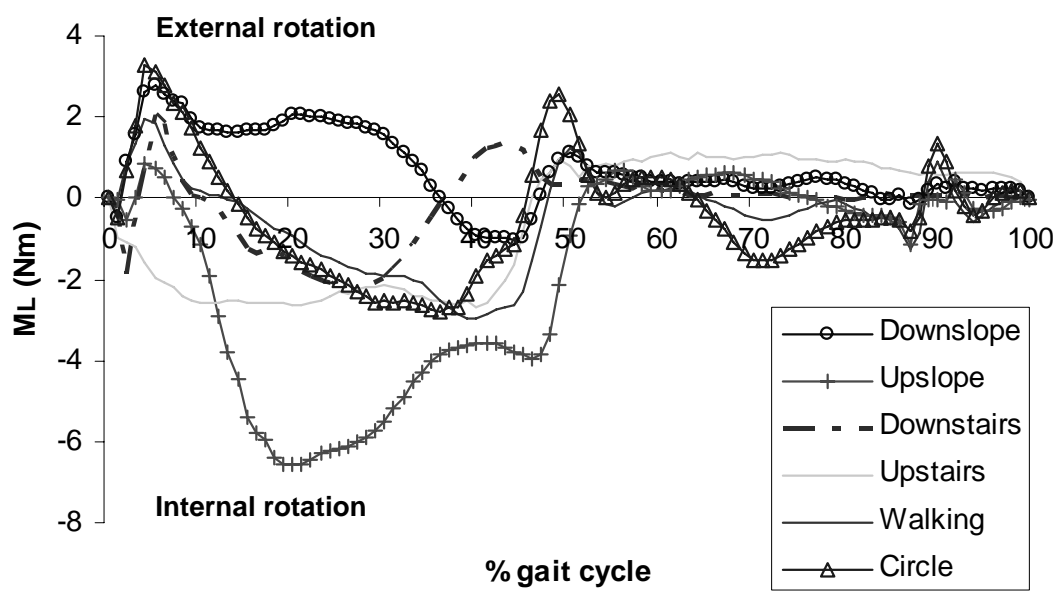

Figure 5. Typical external/internal rotational moment $\left(\mathrm{M}_{\mathrm{L}}\right)$ for in the six different activities 


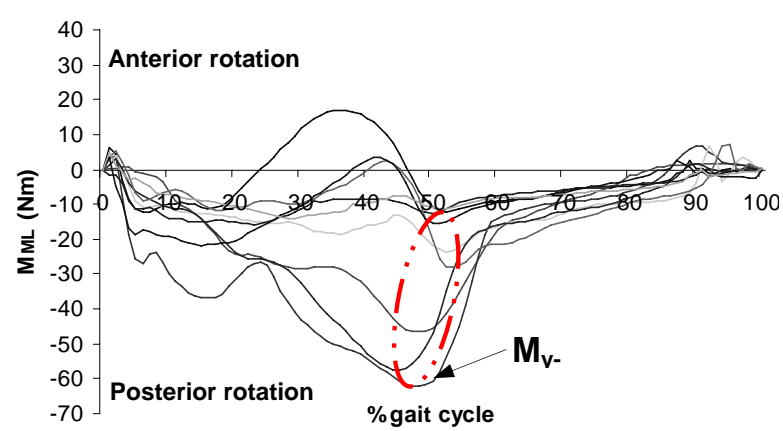

(a) Downslope

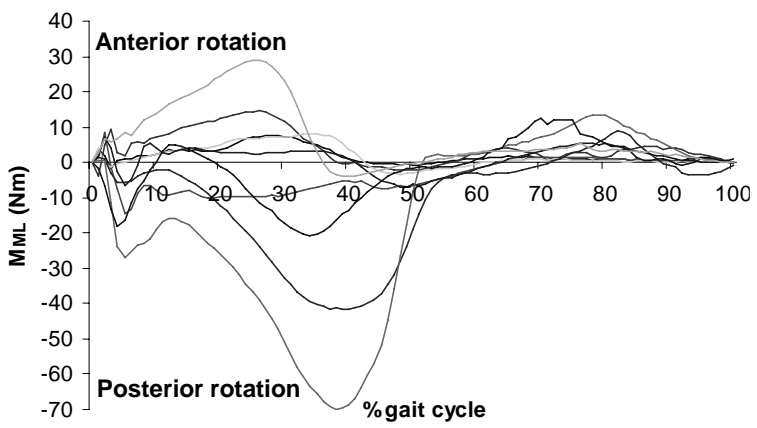

(b) Downstairs

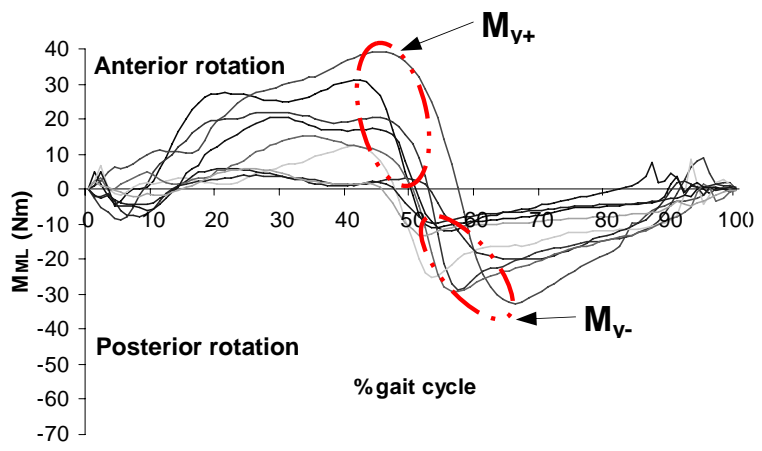

(c) Upslope

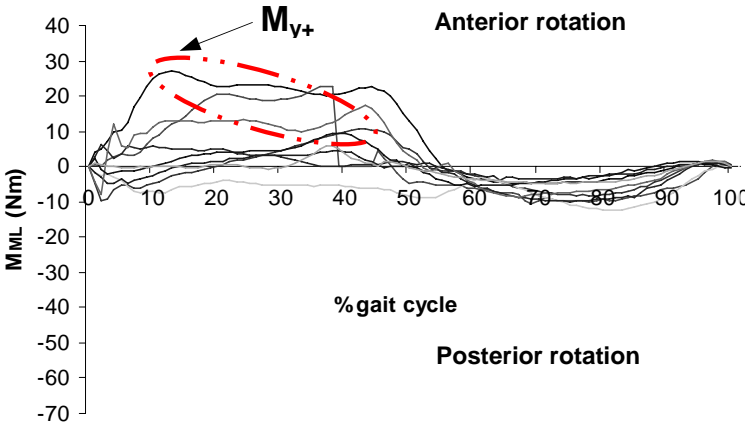

(d) Upstairs

Figure 6. Moment about the mediolateral axis $\left(\mathrm{M}_{\mathrm{y}}\right)$ for all subjects managing (a) downslope, (b) downstairs, (c) upslope, and (d) upstairs. 